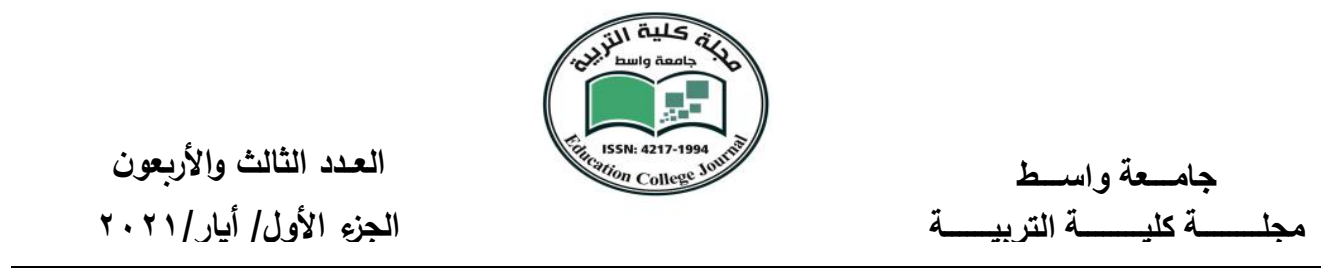

\title{
دور تدريس مادة القرآن الكريم والتربية الإسلامية في سلوك طلبة المرحلة الاعدادية من وجهة نظر المدرسيّن
}

م.م. جاسم محمة سهيل

وزارة التربية / مديرية تربية بذاد الكرخ الثانيــة

ملغص البحث

يهذف البحث التعرف على دور تدريس مادة القران الكريم والتربية الاسلامية في سلوك طلبة الكابة

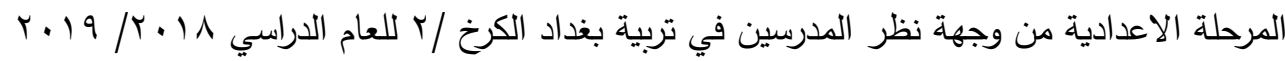

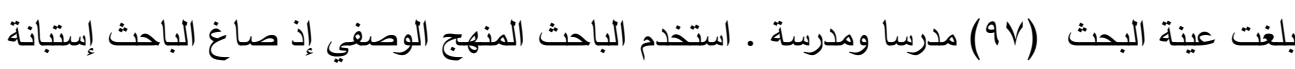

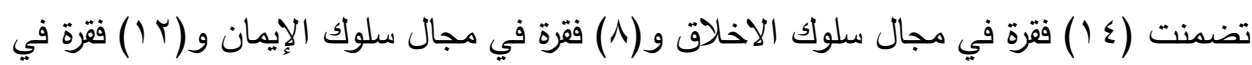
مجال السلوك العلمي. وقد توصلت الدراسة إلى النتائج التالية

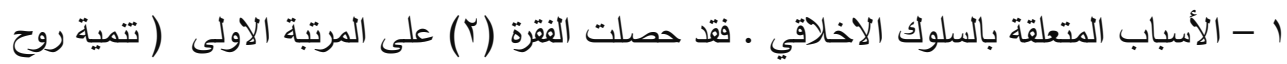

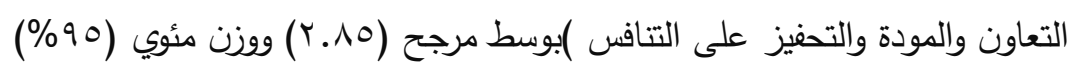

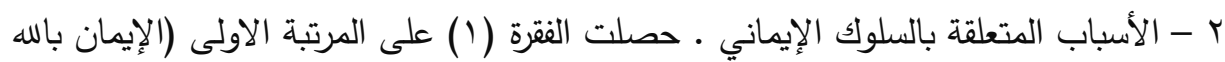

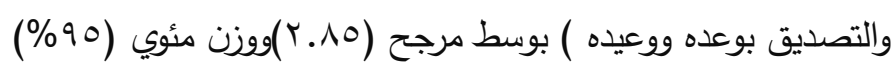

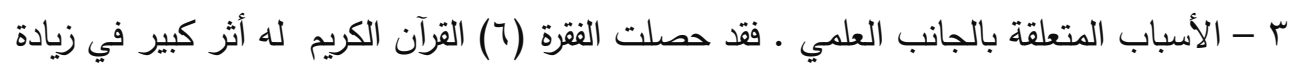

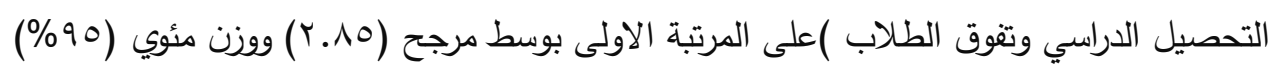
الكلمات الأفتاحية: ( تدريس ، القرآن الكريم ، سلوك ) الكرنة الاولى بوسط

\section{The role of teaching the Holy Quran and Islamic Education in the behavior of students Middle school from the teachers' point of view} Abstract

The research aims at the impact of teaching the Noble Quran and Islamic education on the behavior of middle school students from the pointof view of teachers in tge education of Baghdad Al-karkh $/ 2$ for the academic year 2018/2019. The research has reached 97 teachers.

The researcher drafted a questionnaire that inciuded 14 paragraphs in the field of ethical behavior , 8 paragaphs in the field of Aleman behayloe and 12 paragraphs in the field of scientific behavior . 
العدد الثالث والأربعون

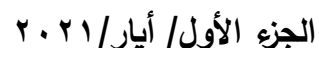

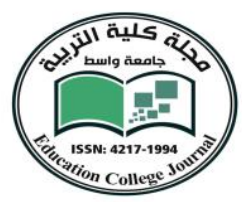

: Reaearch results

The study reached the following resuits

1. Reaspns related to ethical behavior : paragraph 2 was ranked first (developing the spirit of cooperation intimacy and motivting competition) with a weighted average (2.85) and a percentage weight (95\%).

2.Reasons related to the behavior of faith .paragraph (1) was ranked first (belief in God and believing in his promise and promises ) with a weighted average ( 2.85 ) and a percentage weight (95\%)

3.Reasons related to scientific behavior : paragraph (6) the Noble Quran has a great effect in increasing academic achievement and student achievement ranked first with a weigted average (2.85) and a percentage weight (95\%) Opening Words (Teaching, The Holy Quran, Behavior)

\section{الفصل الأول : التعريف بالبحث مشكلة البحث :}

كون الباحث تدريسي لمادة القرآن الكريم والتربية الإسلامية للمرحلة الاعدادية ولقربه من الطلبة بحكم تدريسه لهم لهذه المادة الجليلة ومن خلال الأسئلة التي كان الطلبة يوجهها له ومناقشته معهم في بعض الموضوعات المهمة في مادة القرآن الكريم والتربية الإسلامية لمس أن هناك تغير في السلوك الأخلاقي والعلمي والإيماني لاى طلبة المرحلة الاعدادية نتيجة دراستهم ومراجعتهم لموضوعات هذه المادة وإيماءً لما تقدم فقد تحدد مشكلة البحث بالسؤال الاتي • (ما دور تدريس مادة القرآن الكريم والتربية الاسلامية في سلوك طلبة المرحلة الاعدادية من وجهة نظر المدرس ) وسيتم الإجابة على هذا السؤال من خلال الدراسة الحالية

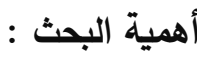

" الاسلام دين ودولة ، وشريعة لهها ، والدعامة الأساس في بناء المجتمع إذ تتبع الفضيلة منه وتتضح من تعاليمه القيم الإنسانية وعلى هدى فلسفته يتعامل الناس ، فالقيم الثابتة التي يمنحها القانون الآلهي هي صمام الأمان في الدنيا والاخرة .وديننا الحنيف هو منهاج الحياة ـ يعنى بالفرد وبالمجتمع بالناحية المادية والروحية معاً ، ويوضح معنى العبادة ويؤكد قيمة العمل فضلاً عن عنايته بشؤون الحياة وتتظيم شؤون الدنيا جميعها ، بوصفه طريقاً وحيداً لاخرة سعيدة. فيتناول شؤون الحياة جمعا بالتحليل والتتظيم من اقتصاد وسياسة وحكم وتربية وعلوم واجتماع فالقرآن الكريم ذلك الكتاب لتصؤي

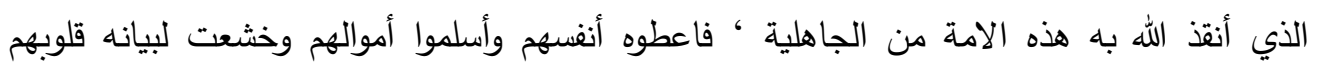


العدد الثالث والأربعون

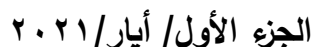

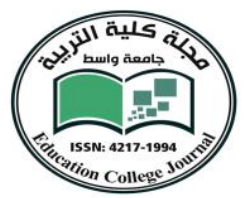

،وتقوت بتلاوته ألسنتهم وقامو به والناس نيام فسرى فيهم كما يسري الماء في ارض قد اجدبت

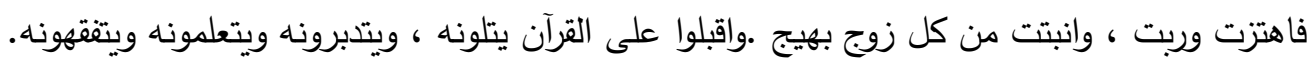

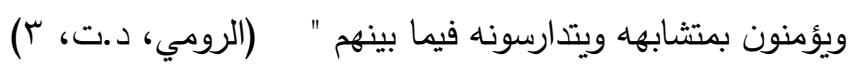

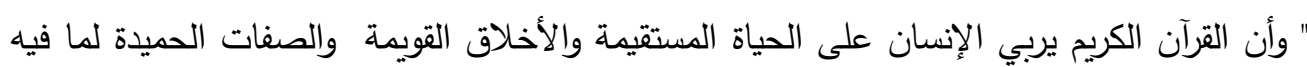

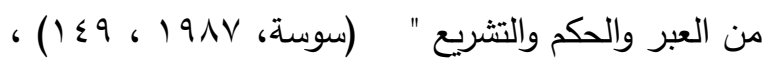

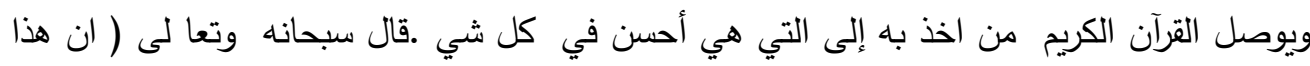

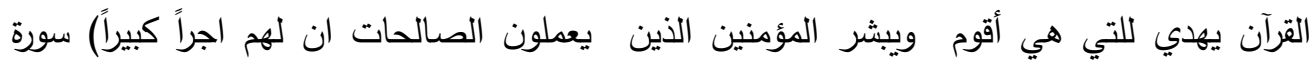

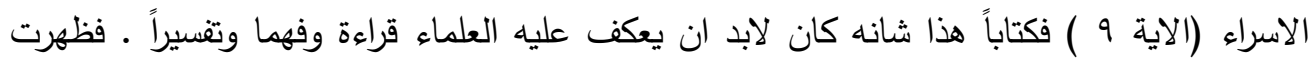

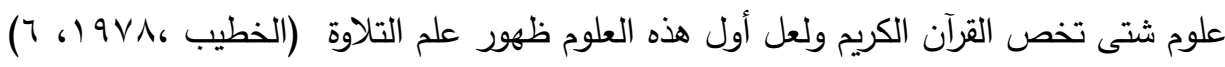

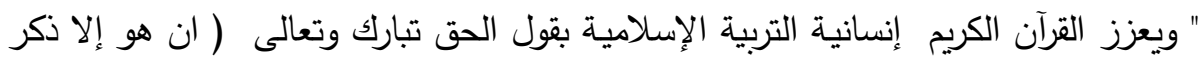

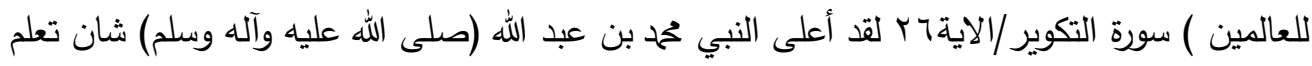
القرآن وتعليمه ، فجعل الذين يتعلمونه ويعلمونه هم خير الناس بقوله صلى الآه الله عليه وسلم ( خيركم

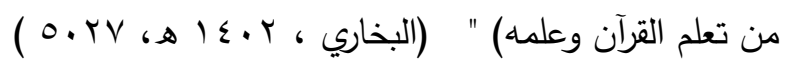

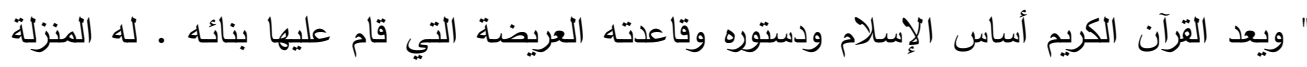

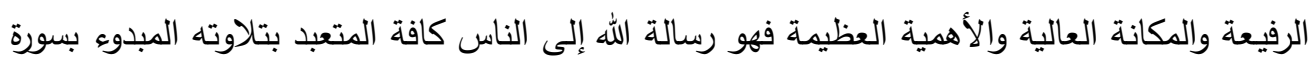

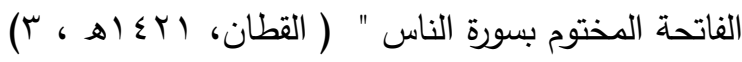

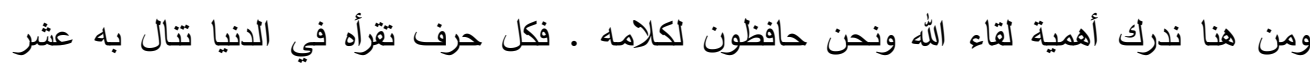
حسنات . وسوف يرفعك الله به اعلى الدرجات يوم القيامة ـاما الفوائد الدنيوية لمن يحفظ كلام الله في صدره بإعتبار ان أفضل عمل على الاطلاق ممكن ان يقوم به الإنسان هو دراسة القرآن الكريم

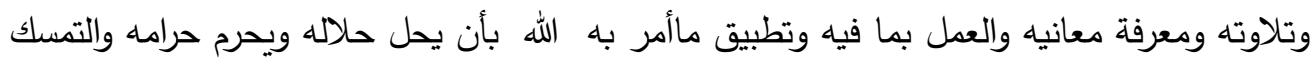

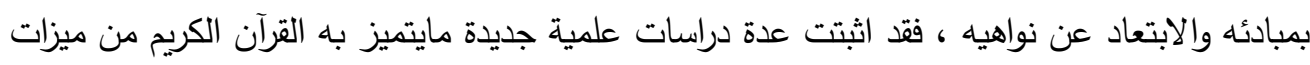

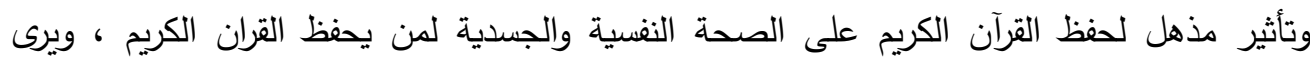

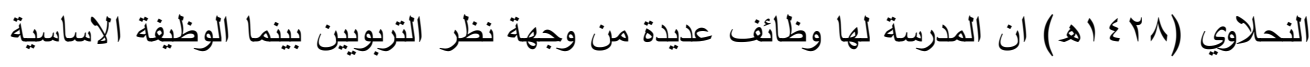

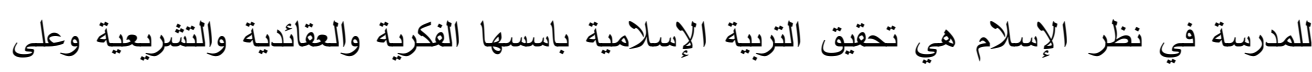

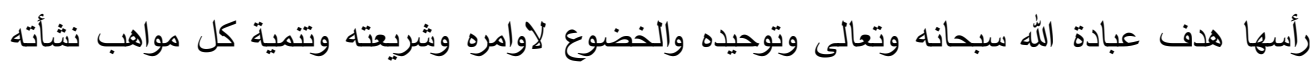

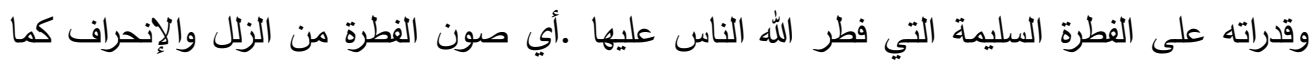


العدد الثالث والأربعون

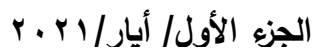

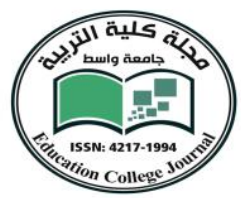

جاء في الحديث عن الرسول صلى الله عليه وآله وسلم : كل مولود يولد على الفطرة فأبواه يهودانه

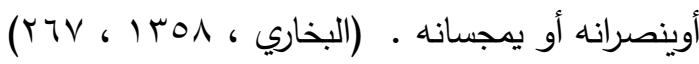
ولأن التربية تسعى لبناء الإنسان كونه طاقة بشرية ودعامة رئيسة في قوة المجتمع وتقدمه

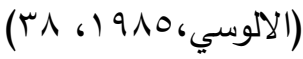

لذا عدت التربية وظيفة أساسية يحافظ بها المجتمع على وجوده وتطوره واستمراره(القاسم،9,0,9 1 ) واذا كان للتعليم كل هذا التأثير على الفرد المسلم فأن تأثيره يكون أشد واقوى في المرحلة الثانوية هات ويرى الوزان " ضرورة ألأهتمام بتربية النشئ في هذه المرحلة ، ويرى انها المرحلة المناسبة لإعطاء الطلاب جرعات كافية من المواد الثرعية لأن الطالب فيها يمر بمرحلة المراهقة التي تتميز بميزات جسمية ، عقلية ، انفعالية ، اجتماعية تجعلها من انسب المراحل لغرس القيم والعادات والاتجاهات

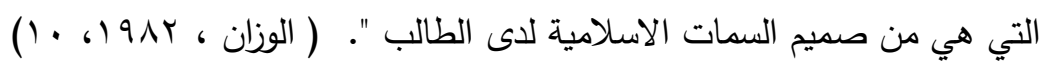

إذ إن الدارس للقرآن الكريم لابد له من ان يقطف ثمار مدارسته للقرآن الكريم التي بينها الرسول الكريم (صلى الله عليه وسلم ) مايتعلق بالأجر والثواب والبركة في الدنيا والآخرة ، وانه يزيد الإيمان ويحي القلوب ويطهر النفوس ويهذبها ويولا الطمانينة ويبعث في الروح السرور وألانشراح ، والابتعاد

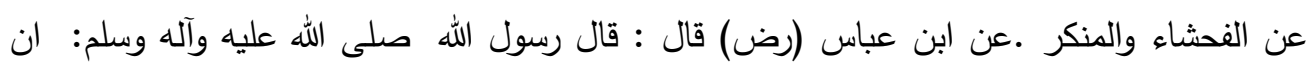

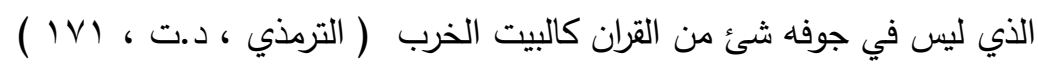
" ان التربيةعصب الحياة وذلك لانها ترمي إلى مساعدة الإنسان على إكتساب أنواع السلوك المتوقع

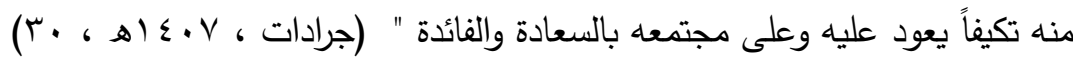
" فالتزبية علم وصناعة تزود الاجيال الصاعدة بالقوى والقدرات والمهارات التي تمكنها من تطوير

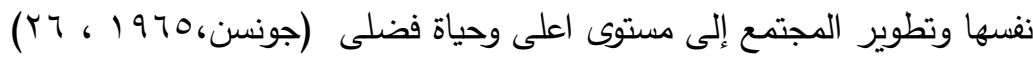
وتتميز التربية الإسلامية بمنهج متفرد في رسائله وفي أهدافه . وان البشرية لم تعرف في تاريخها كله نظاماً تربوياً بهذه السمة وهذا الثمول وهذه الإحاطة ، إن مناهج التربية المختلفة تهدف إلى إعداد المواطن الصالح ، اما التربية الإسلامية فتسعى إلى تحقيق هدف اكبر وأسمى ، وهو إعداد

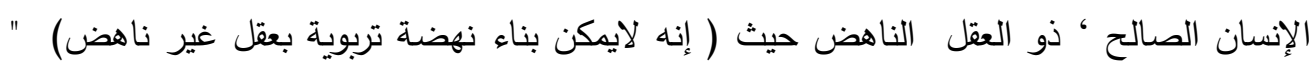

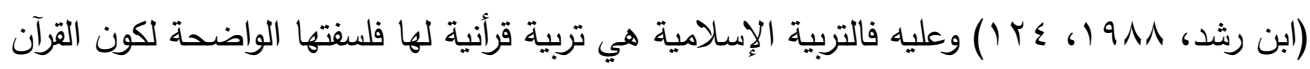
الكريم في حقيقة الأمر منهج متكامل للتربية الإسلامية لم يترك صغيرة ولاكبيرة 


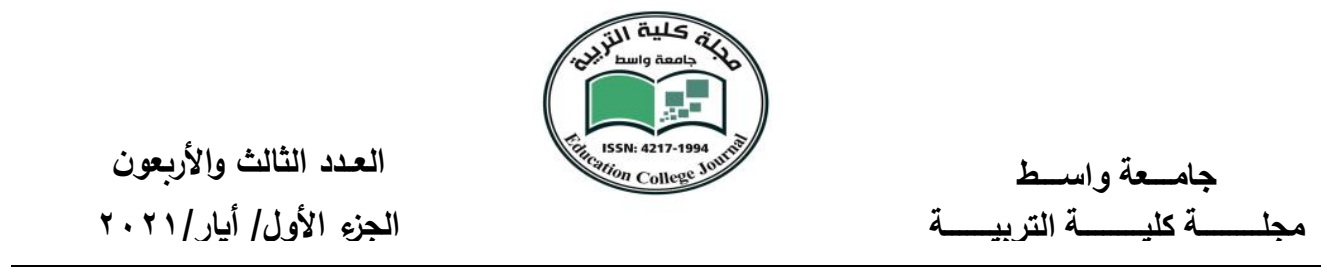

ومن أبرز سمات التربية ألإسلامية عن غيرها بما يأتي.

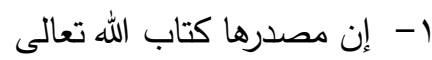

r- إنها ليست معلومات يحفظها الطلاب بل تعاليم ومعاملات r- تهدف إلى خلق اتجاه نحو القيم الإسلامية ع - إكتساب المتعلمين مهارات سلوكية تظهر على حياتهم اليومية وتعاملهم النهاه

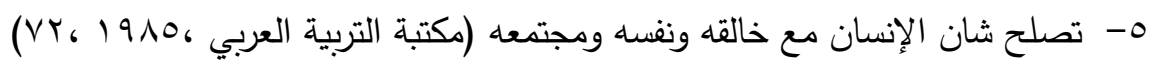

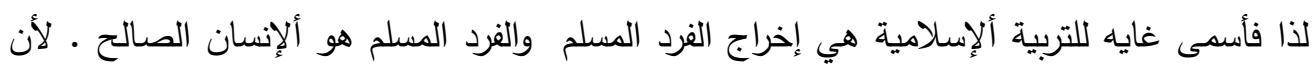

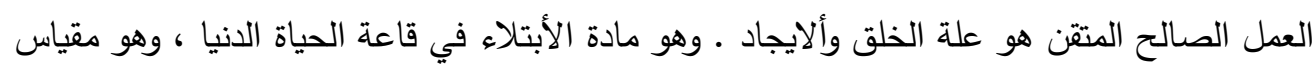
النجاح في ألآخرة قال تعالى (الذي خلق الموت والحياة ليبلوكم أيكم أحسن عملاً وهو العزيز الغفور )

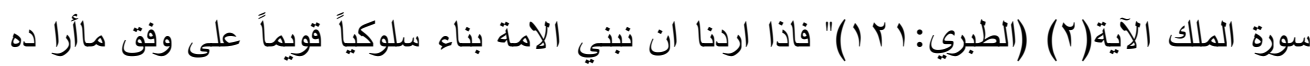

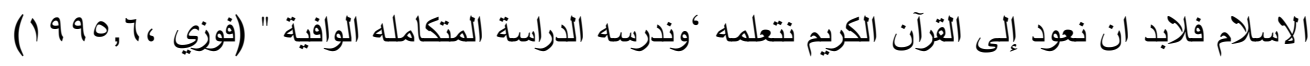

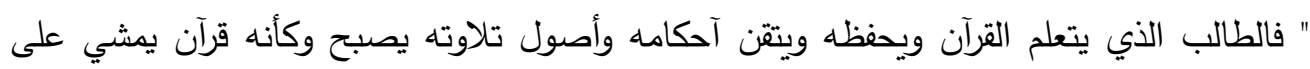

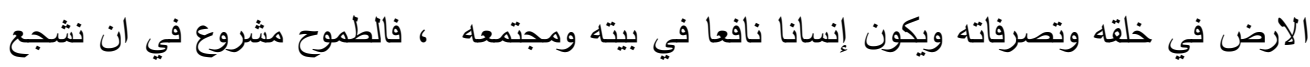
الطلبة ونحفز ميولهم واتجاهاتهم وتوفير الرغبة لديهم في معاهدة كتاب الله ، وتعلم التلاوة الصحيحة

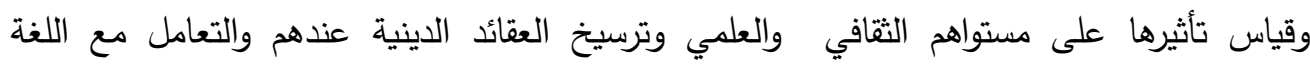

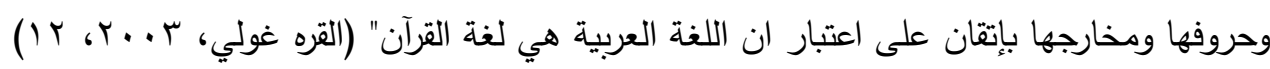

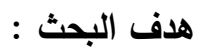
يهدف هذا البحث إلى معرفة دور تدريس مادة القرآن الكريم والتربية الإسلامية في سلوك طلبة

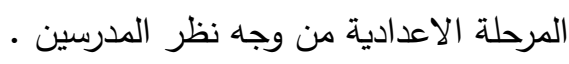

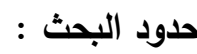
1- الحد الدكاني يتحدد هذا البحث بمدرسي مادة القرآن الكريم و التربية الإسلامية في المدارس

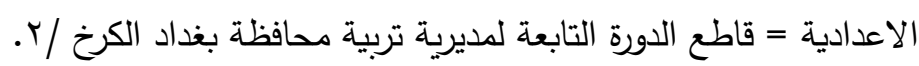

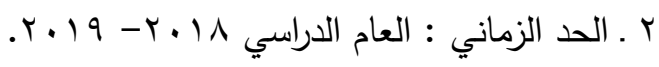

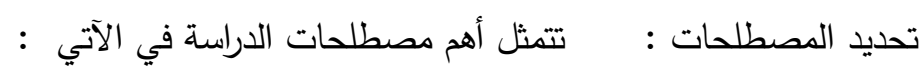

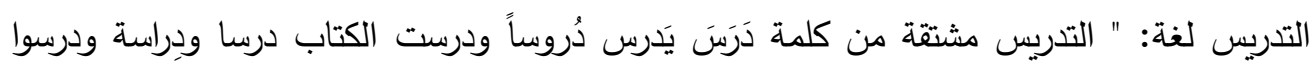

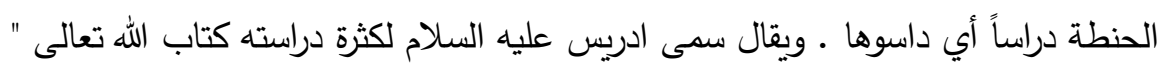

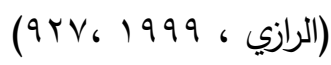


العدد الثالث والأربعون

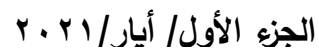

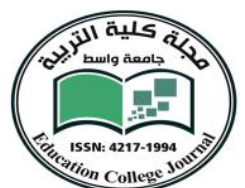

التدريس اصطلاحاً: عرفه المنوفي انه " عملية أجتماعية تتكون من مجموعة من الأنشطة والأجراءات

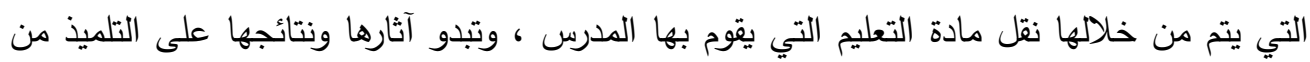

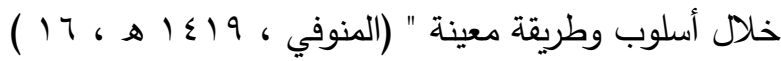

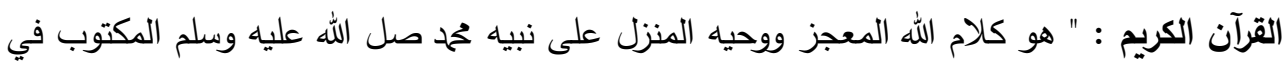

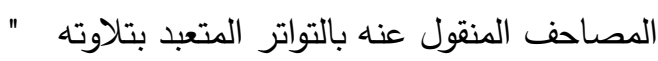
وقيل أيضاً "بانه اللفظ المنزل على النبي صل صلت الله عليه وسلم من اول سورة الفاتحة الى اخر سورة " الناس " تعريف التربية الإسلامية:"هي تنمية جميع جوانب الثخصية الاسلامية ـ الفكرية والعاطفية والجسدية

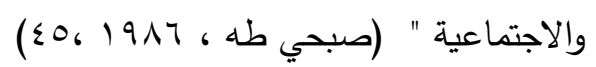

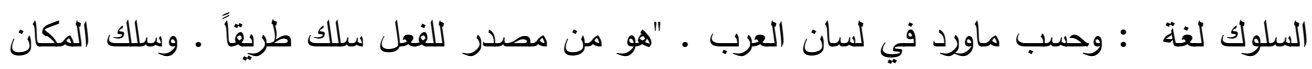

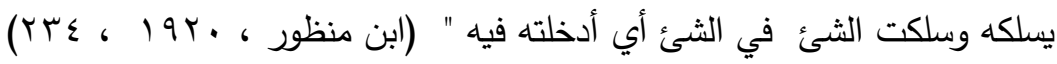

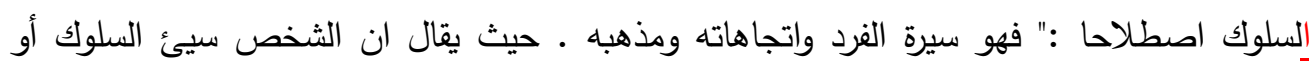

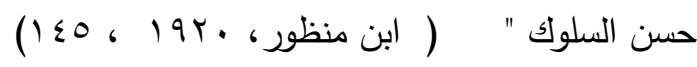
التعريف الاجرائي : هم مفردات منهج مادة القرآن الكريم والتربية الاسلامية والمتضمن ( القران الكريم والتربية الاسلامية

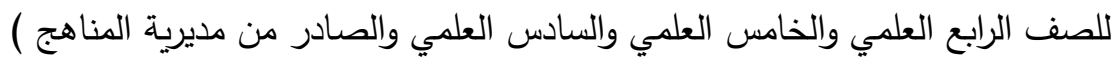


العدد الثالث والأربعون

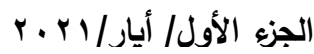

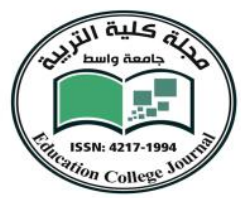

\section{الفصل الثاني}

تضمن هذا الفصل عرضاً للدراسات السابقة الخاصة بتدريس مادة القرآن الكريم والتربية الإسلامية

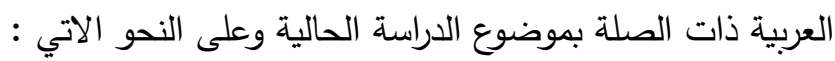

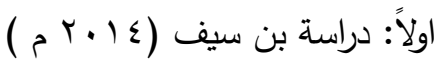

وكانت بعنوان ( أثر حلقات تحفيظ القرآن الكريم على التحصيل الدراسي والقيم الخلقية) هافت الاراسة إلى التعرف على علاقة التحاق الطلبة بحلقة تحفيظ القران الكريم بالتحصيل الدراسي

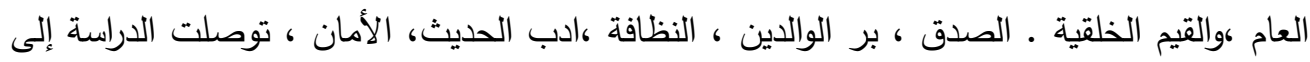

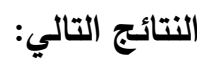
1- ارتفاع التحصيل الدراسي للطلاب باختلاف صف التحاقهم ،أي كلماطالت مدة التحاقهم بحلقة

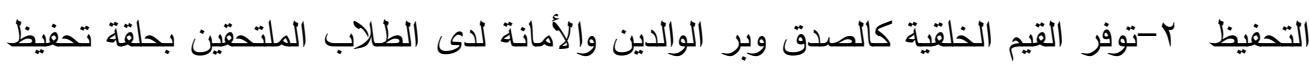
القرآن الكريم

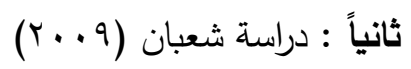

وكانت بعنوان ( من الاثار الإيمانية لتعليم لتعليم وتعلم القرآن الكريم على الفرد والمجتمع ) هدفت الدراسة إلى معرفة الإجابة عن التساؤلات التالية 1- ماالمقصود بالقرآن الكريم ومامعنى الاثار الايمانية ومامفهوم تعليم القرآن الكريم •

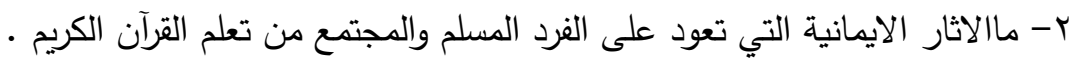

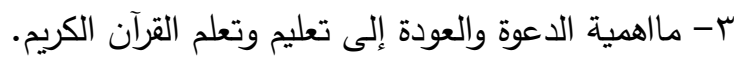

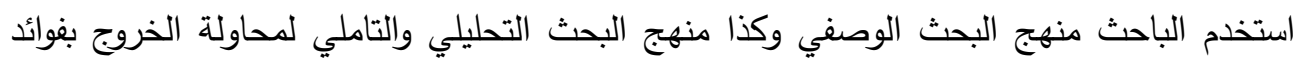
علمية مهمة ودقيقة ، توصلت الدراسة إلى اهم النتائج 1- ان القرآن الكريم كلام الله الذي انزله على النبي تحمد ( صلى الله عليه وآله وسلم) المعزل

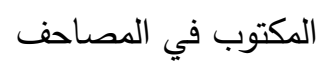
r- ان القرآن اخلاق الأفراد فيصلحها وبصلاحها تصلح الامة.

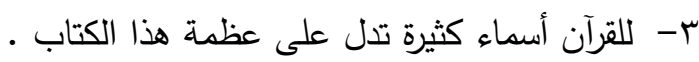
ع- لتعليم القرآن أهمية قصوى فهو يعيد الأفراد الى ربهم وتمسكهم بدينهم. ه- لحفظ القرآن تاثير كبير على تقويم عقول الأولاد وشخصيتهم فهو يعودهم الفضائل السلوكية والأخلاق. 
العدد الثالث والأربعون

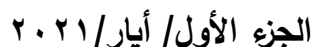

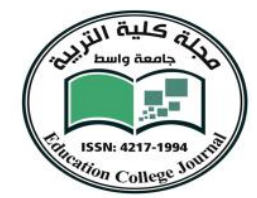

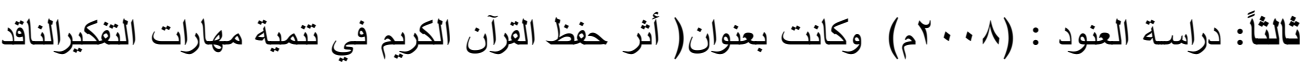

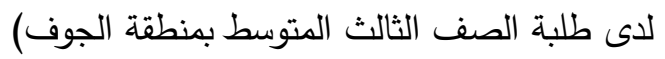

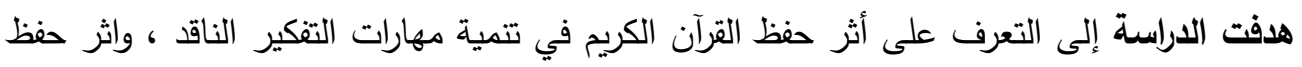

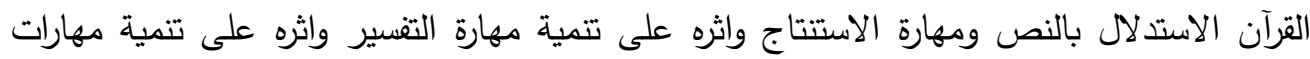
البحث عن العلاقات

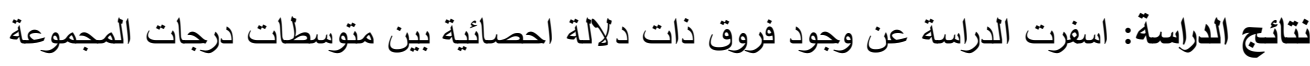
التجريبية ( الحافظات ) ومتوسط درجات المجموعة الضابطة ( غير الحافظات ) في مهارات الاستدلال بالنص ،مهارة الاستنتاج ، مهارة البحث عن العلاقات ، مهات التهارة التفسير مؤشرات ودلالات عن الدرسات السابقة بعد اطلاع الباحث على الدرسات السابقة التي تتاولت مواضيع القرآن الكريم والتربية الإسلامية ، يحاول الباحث مناقثة هذه الدراسات من حيث الاهداف والمنهجية وماتوصلت اليه من نتائج

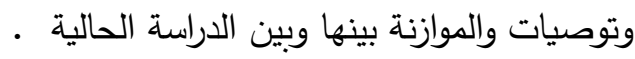
أولاً: أهداف الدراسات السابقة والكونة

1-هدفت دراسة بن سيف( ؟ ا • آم 1) إلى معرفة (أثر حلقات تحفيظ القران الكريم على التحصيل الدراسي والقيم الخلقية ) r- هدفت دراسة شعبان (9 . . F م) الى معرفة اثار الايمانية وتعليم وتعلم القران الكريم على الفرد والمجتمع

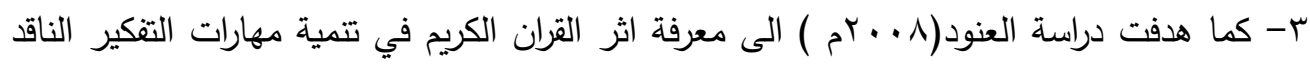
وتتميتها ع - اما الهدف من الدراسة الحالية فهي معرفة دور تدريس القران الكريم والتربية الإسلامية في سلوك

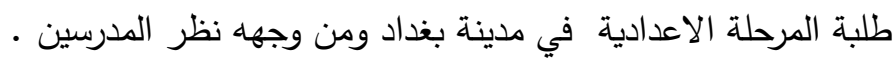

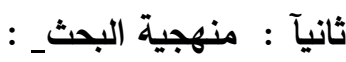

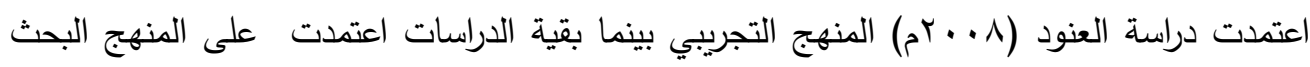

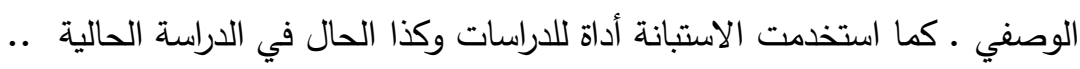
ثالثًا : الوسائل الاحصائية كانت اكثر الوسائل الاحصائية استخداما في استخراج النتائج هي النسبة المؤية .معادلة الوسط

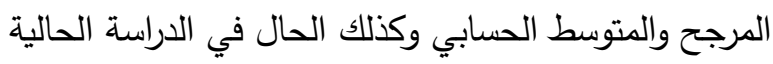




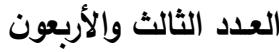

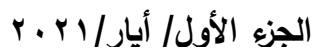
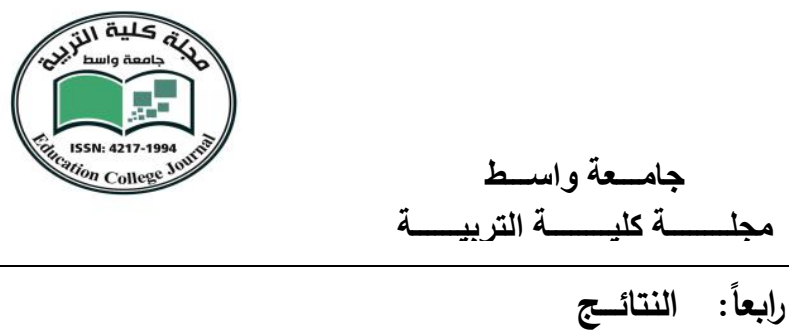

تباينت نتائج الدراسات السابقة تبعا لتوجه الدراسة واهدافها واساليب بحثها وحجم عينتها فقد التقت نتائج الدراسات السابقة مع الدراسة الحالية في لتاني 1-ان القرآن الكريم كلام الله المعجز المنزل على نبيه محمد صل الله عليه وسلم

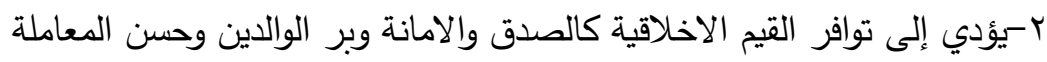
ب-القرآن الكريم يمد الانسان بالقوة الفكرية والايمانية وقد افاد الباحث من الدراسات السابقة من خلال الاطلاع على منهجيتها واجراءات وبناء الاستبانه وتحديد مجتمع الدراسة والوسائل الاحصائية.

\section{الفصـل الثالــث}

اجراءات البحث

يتضمن هذا الفصل منهج البحث الذي استعمله الباحث في بحثه ويحدد مجتمع البحث وكيفية

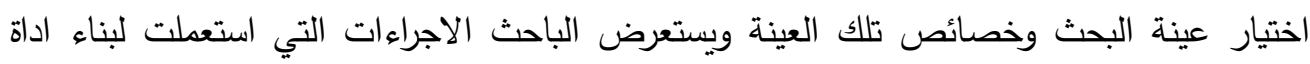

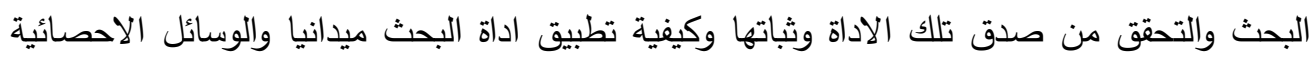

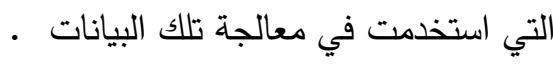
اولاً: منهج البحث .: "استعمل الباحث المنهج الوصفي الذي يعتمد على دراسة الواقع ويهتم بوصفها

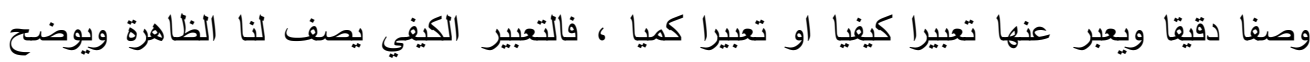

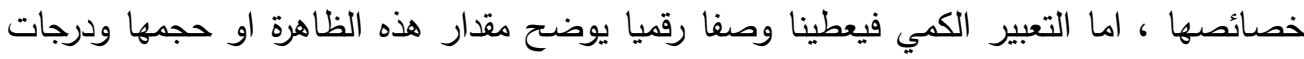

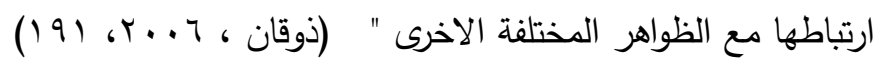

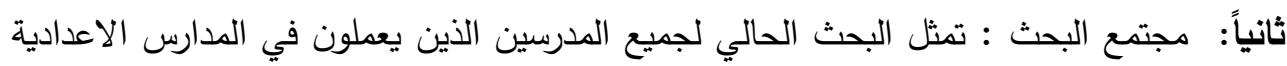

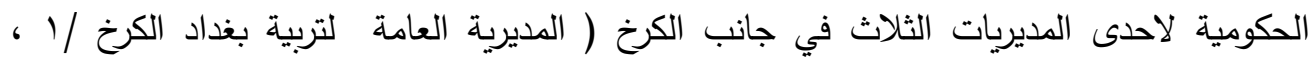

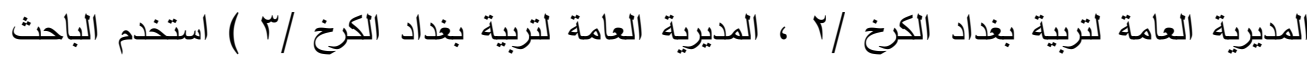

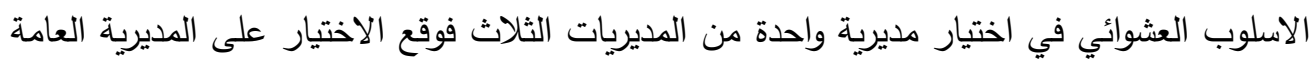

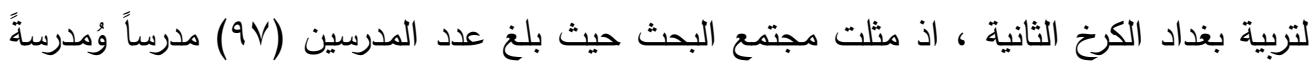

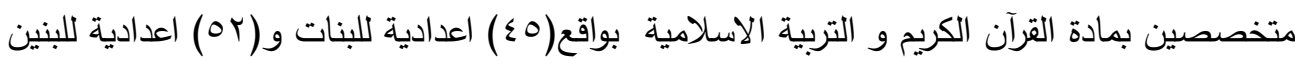

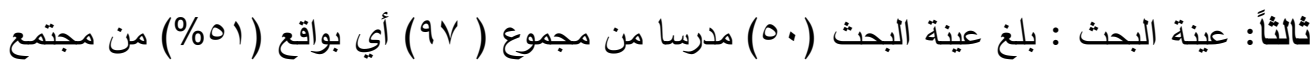
البحث 
العدد الثالث والأربعون

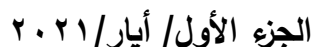

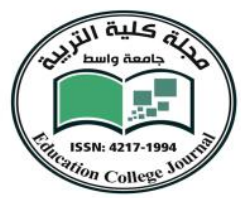

رابعاً: أداة البحث: تم اعداد اعداد اداة البحث وه استبانة البحث بصورتها الاولية وكتابة فقراتها لتعبر

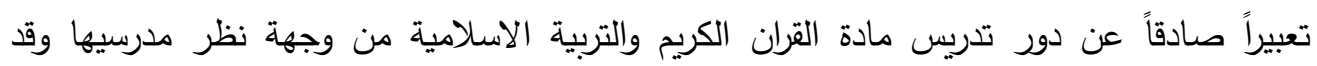

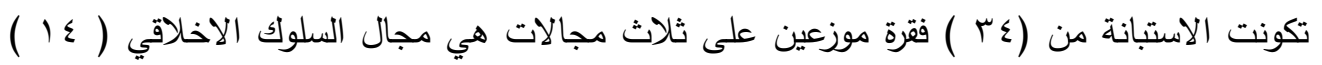

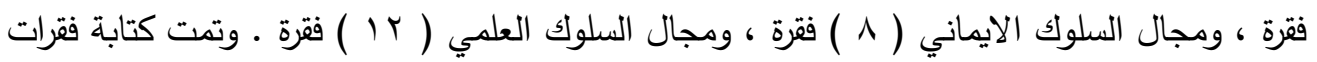
الاستبانة بعدد من المصادر وخبرات الباحثين والدراسات السابقة وتكونت الاجابات من من ثلاث الاثل

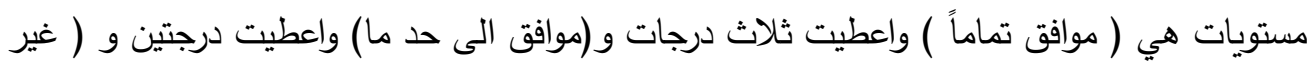

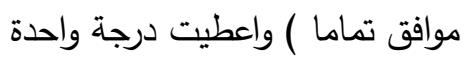
الصدق الظاهري للاستبانة

قام الباحث بعرض الاستبانة في صورتها الاولية على مجموعة من المحكمين والمختصين

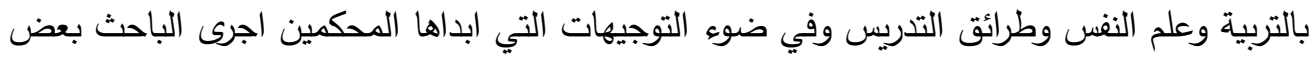

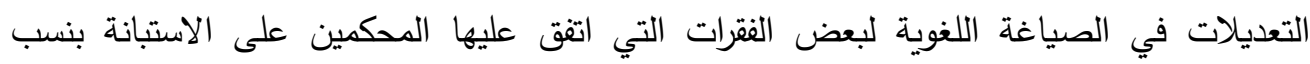
(\%^•)

صدق الاتساق الداخلي : تم تطبيق الاستبانة على عينة استطلاعية مكونة من ( • ( ) مدرسا للتاكد

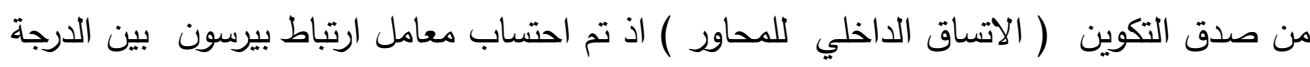

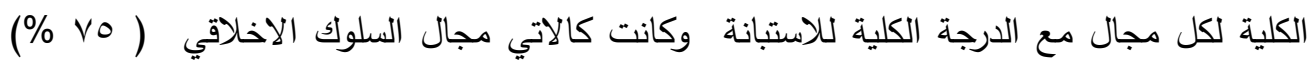

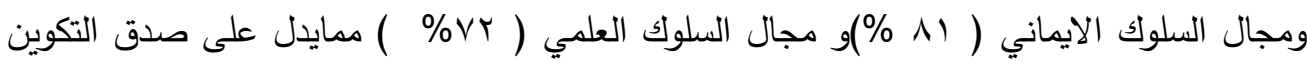
الداخلي للاداة عالي الارتباط عند مستوى دلالة ( (...) وهذا يعني ان الاستبانة تتمتع بدرجة عالية علئ

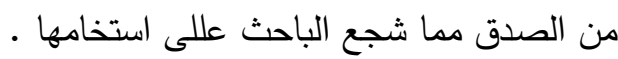
الثبات :

احتسب الباحث ثبات الاداة على العينة الاستطلاعية باستعمال معامل الفا كرونباخ بطريقة التجزئة

النصفية اذ بلغ ( \% \% ) وهذا يدل على ثبات عالي مما حدا بالباحث على استعمال الاستبانة .

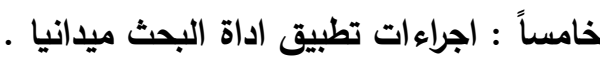
طبق الباحث اداة البحث على عينة البحث وقد اشرف الباحث على تطبيق الاستبانةواستلام الاجابات

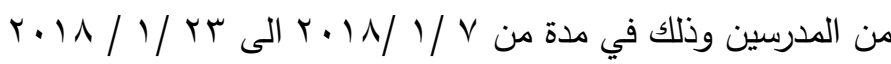

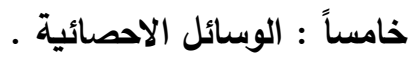

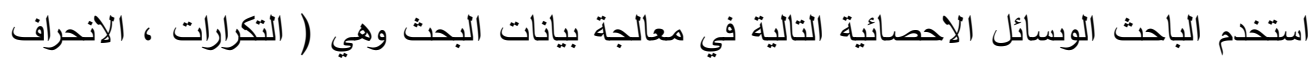

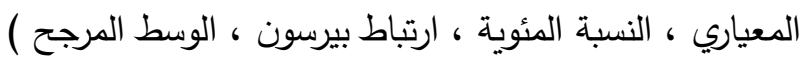


العدد الثالث والأربعون

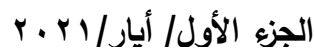

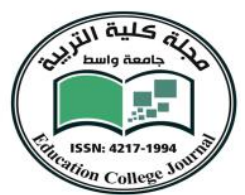

الفصـل الرابع

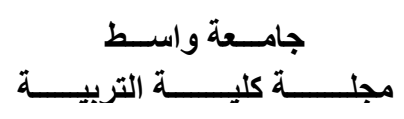

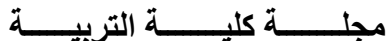

\section{عرض النتائج وتفسيرها}

يعرض الباحث في هذا الفصل النتائج وتفسيرها والاستتاجات والتوصيات والمقترحات : ولاً : النتائج : عرض النتائج: بعد تفريغ اجابات المدرسين والمدرسات ومعالجتها احصائياً ظهرت

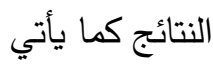

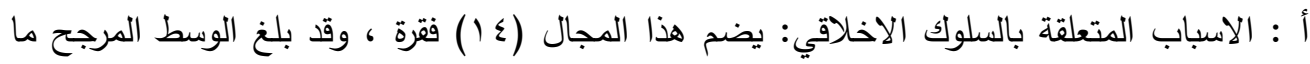

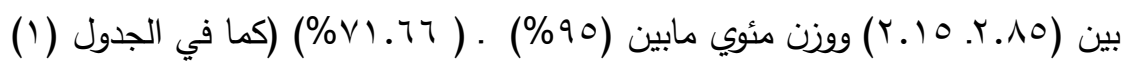
الجدول رقم (1) فقرات السلوك الاخلاقي

\begin{tabular}{|c|c|c|c|c|c|c|}
\hline \multirow{2}{*}{ 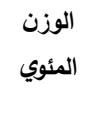 } & \multirow[t]{2}{*}{ 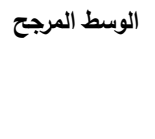 } & \multicolumn{3}{|c|}{ التكرارات } & \multirow[t]{2}{*}{ الفقرة } & \multirow[t]{2}{*}{ 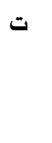 } \\
\hline & & معارض & محايد & موافق & & \\
\hline $88.33 \%$ & 2.65 & 2 & 3 & 15 & التأدب باداب القران من خلال الاحسان للاخرين & 1 \\
\hline $95 \%$ & 2.85 & 1 & 1 & 18 & تنمية روح التعاون والثودة والتحفيز على التنافس & 2 \\
\hline $83.33 \%$ & 2.5 & 2 & 6 & 12 & تهذيب السلوك من خلال رسم القدارت في المجتمع وبكافة & 3 \\
\hline $91.66 \%$ & 2.75 & 3 & 1 & 17 & تنمية روح الخوة والتسامح بين الطلبة. & 4 \\
\hline $85 \%$ & 2.55 & 3 & 3 & 14 & التأدب باخلاق القران. & 5 \\
\hline $88.33 \%$ & 2.65 & 2 & 3 & 15 & حفظ المجتمع من شر جنوح الشباب من خلال معرفة & 6 \\
\hline $83.33 \%$ & 2.5 & 2 & 6 & 12 & الاعتبار بامثلة القران وقصصه & 7 \\
\hline $76.66 \%$ & 2.3 & 4 & 6 & 10 & ترسيخ القيم والمبادئ التي يدعو اليها الاسلام & 8 \\
\hline $71.66 \%$ & 2.15 & 5 & 7 & 8 & تنظيم العلاقات والمعاملات بين أفراد المجتمع & 9 \\
\hline $76.66 \%$ & 2.3 & 5 & 4 & 11 & تزكية النفس & 10 \\
\hline $83.33 \%$ & 2.5 & 3 & 4 & 13 & اختيار الصحبة الصالحة بعد ماعلموا ماللصحبة من تأثير . & 11 \\
\hline $88.33 \%$ & 2.65 & 2 & 3 & 15 & انحسار الظواهر السلبية بين الطلبة & 12 \\
\hline $88.33 \%$ & 2.65 & 1 & 5 & 14 & التأدب باخلاق القران & 13 \\
\hline $91.66 \%$ & 2.75 & 1 & 3 & 16 & تنمية السلوك العام والمتضمن الصفات الاخلاقية كالصدق & 14 \\
\hline
\end{tabular}


العدد الثالث والأربعون

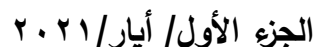
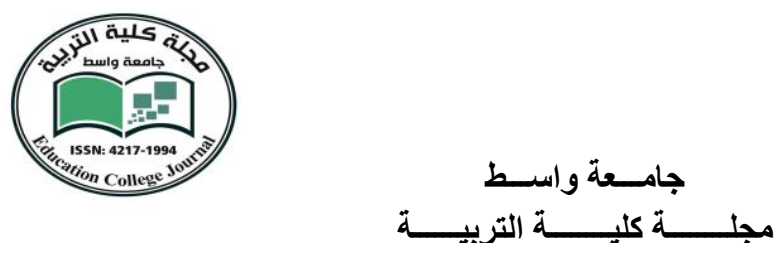

يتضح من الجدول رقم (1) ما يأتي :

1- انّ الفقرة (r) (تتمية روح التعاون والمودة والتحفيز على التتافس) قد حصلت على المرتبة الأولى (باتى

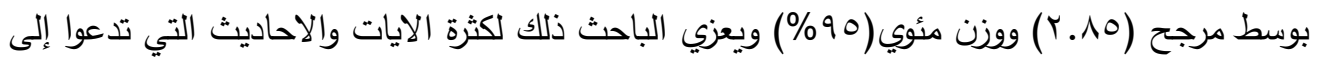

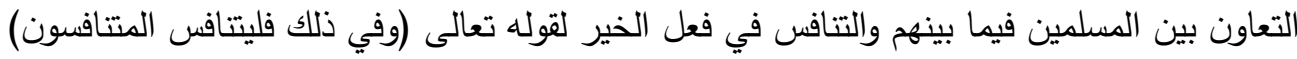

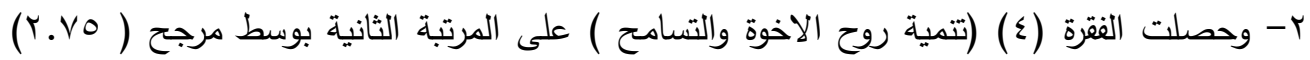

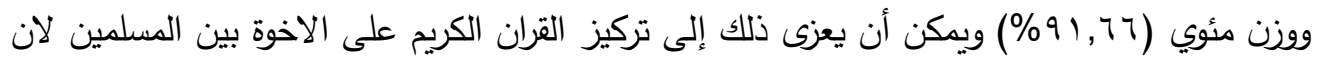

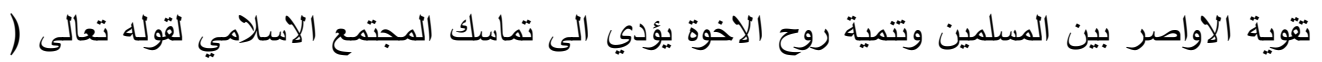

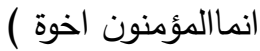
r- وحصلت الفقرة (9) ( تنظيم العلاقات والمعاملات بين افراد المجتمع ) على المرتبة الثالثة بوسط

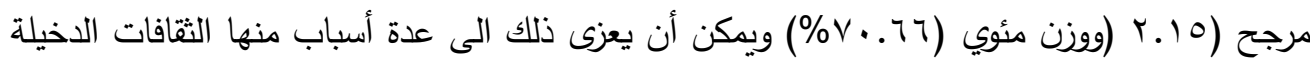

وانتثار المعاملات الربوية والتعامل بالمثل ب: الاسباب المتعلقة بالسلوك الايماني يضم هذالهجال (^) فقرات ، وقد بلغ الوسط المرجح مابين

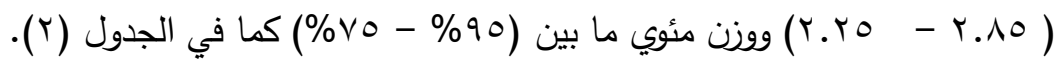
الجدول رقم (ץ) فقرات سلوك الايمان

\begin{tabular}{|c|c|c|c|c|c|c|}
\hline \multirow[t]{2}{*}{ الوزن المئوي } & \multirow[t]{2}{*}{ الوسط المرجح } & \multicolumn{3}{|c|}{ التكرارات } & \multirow[t]{2}{*}{ الفقرة } & \multirow[t]{2}{*}{ ت } \\
\hline & & 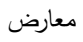 & محايد & 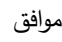 & & \\
\hline $95 \%$ & 2.85 & 1 & 1 & 18 & الايمان باله والتصديق بوعده ووعيده. & 1 \\
\hline $86.66 \%$ & 2.6 & 2 & 2 & 16 & الطهارة والوضوء عند قراءة القران الكريم & 2 \\
\hline $86.66 \%$ & 2.6 & 2 & 4 & 14 & التوكل على الله في الامور كافة & 3 \\
\hline $80 \%$ & 2.4 & 3 & 6 & 11 & تعظيت شأن القراتن الكريم في نفوس الطلبة من خلال & 4 \\
\hline $88.33 \%$ & 2.65 & 2 & 3 & 15 & تلتمية روح الالتزام بالعبادات بشكل أفضل ولاسيما & 5 \\
\hline $75 \%$ & 2.25 & 5 & 5 & 10 & رسوخ عقيدة الايمان لدى الطالب. & 6 \\
\hline $81.66 \%$ & 2.45 & 4 & 3 & 13 & تقوية علاقة الطالب بربه & 7 \\
\hline $90 \%$ & 2.7 & 2 & 4 & 14 & تقويم اللسان وطهارة القلب & 8 \\
\hline
\end{tabular}


العدد الثالث والأربعون

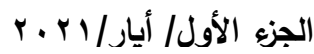

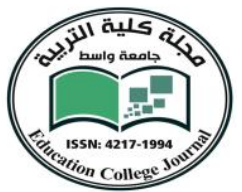

$$
\text { يتضح من الجدول رقم (Y) ما يأتي : (Y) }
$$

1- حصلت الفقرة (1) ( الايمان باله والتصديق بوعده ووعيده ). على المرتبة الاولى بوسط مرجح

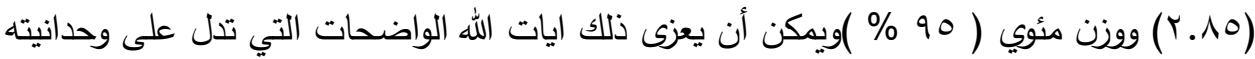

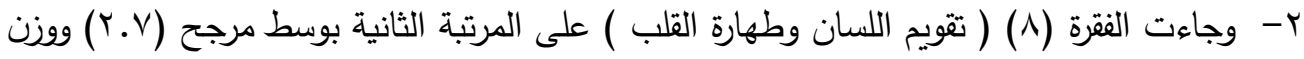
مئوي ( • 9\%) ويمكن أن يعزى ذللك من خلا قراءة القران الكريم باحكام التلاوة ومخارج الحروف r- أما الفقرة (T) (رسوخ عقيدة الايمان لاى الطالب )على المرتبة الثانية بوسط مرجح (Y.Y.) ووزن مئوي (0٪\%) ويعزي الباحث ذلك الى كثرة العقائد والانفتاح الكبير على العالم وانتشار عادات غريبة في المجتمع من خلال حب التقليد من قبل الثباب ج : الاسباب المتعلقة بالجانب العلمي : يضم هذا المجال (Y (Y) فقرة ، وقد بلغ الوسط المرجح

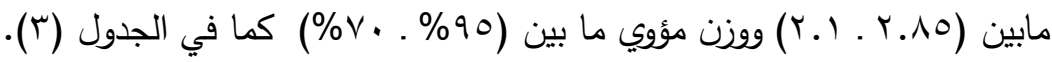
الجدول رقم (ب) فقرات السلوك العلمي

\begin{tabular}{|c|c|c|c|c|c|c|}
\hline \multirow{2}{*}{ 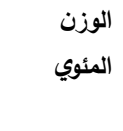 } & \multirow[t]{2}{*}{ الوسط المرجح } & \multicolumn{3}{|c|}{ 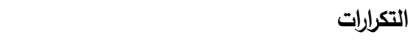 } & \multirow[t]{2}{*}{ 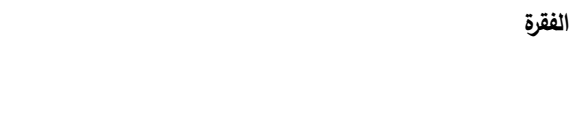 } & \multirow[t]{2}{*}{$ت$} \\
\hline & & 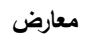 & 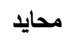 & 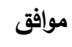 & & \\
\hline $81.66 \%$ & 2.45 & 3 & 5 & 12 & تمكين الطالب من الاستنتاج والاستنباط والابداع. & 1 \\
\hline $78.33 \%$ & 2.35 & 3 & 7 & 10 & تربية العقل بالاستدلال على ماأستدل به القران & 2 \\
\hline $86.6 \%$ & 2.6 & 2 & 4 & 14 & زيادة الابداع من خلال التفكر بايات الله. & 3 \\
\hline $81.66 \%$ & 2.45 & 4 & 3 & 13 & تقويم اللسان والحرص على سلامة اللغة العربية & 4 \\
\hline $70 \%$ & 2.1 & 5 & 6 & 9 & اتقان مهارة التحدث بالفصحى & 5 \\
\hline $95 \%$ & 2.85 & 1 & 1 & 18 & القران له أثر كبير في زيادة التحصيل الاراسي وتفوق الطلاب & 6 \\
\hline $80 \%$ & 2.4 & 4 & 4 & 12 & السمو بعقل الفرد وتزويده بالعلم والمعرفة & 7 \\
\hline 93.33\% & 2.8 & 1 & 2 & 17 & والوقوف على المشاهد القرانية التي توسع الخيال وتنمي الفكر & 8 \\
\hline $85 \%$ & 2.55 & 2 & 5 & 13 & توسيع دائرة النشاط الذهني. & 9 \\
\hline $85 \%$ & 2.55 & 1 & 7 & 12 & التعرف على مضمون النص القراني وربطه بالحياة العامة & 10 \\
\hline $76.66 \%$ & 2.3 & 5 & 4 & 11 & توسع مدارك الطالب من خلال تطرق القران للعلوم & 11 \\
\hline $90 \%$ & 2.7 & 2 & 2 & 16 & رفع قدرة الطالب الادراكية في مجال الفهم والادراك & 12 \\
\hline
\end{tabular}




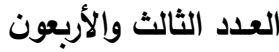

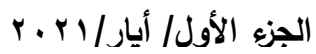
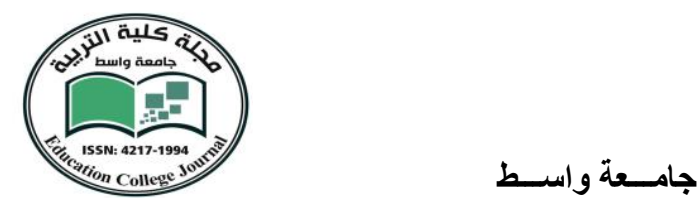

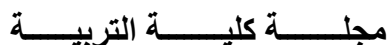

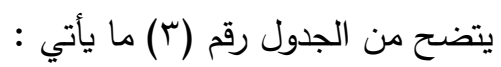

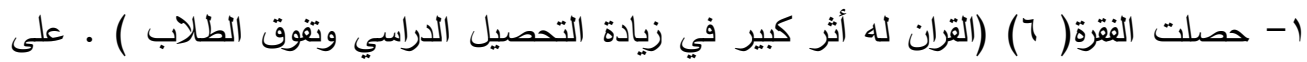

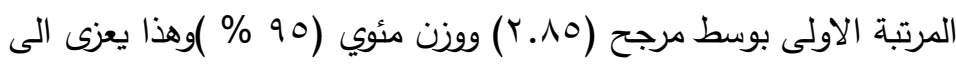

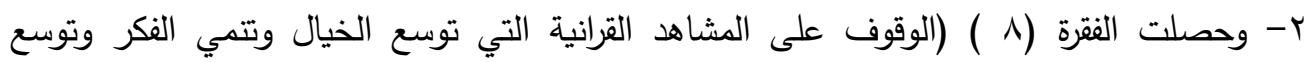

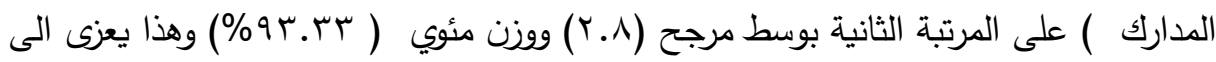

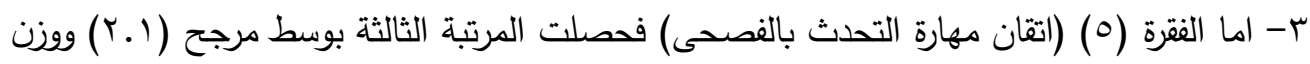

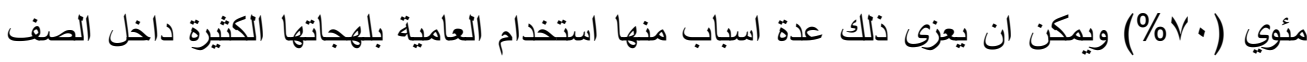
وخارجه وعدم التزام بعض مدرسي القران الكريم ياللغة الفصحى و محاولة بعض بعض الفيات الثباب اظهار

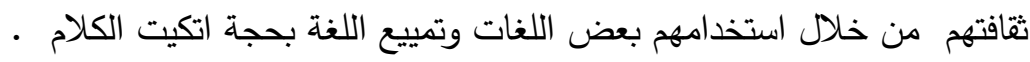

ثانياً : الاستنتاجات

في ضوء النتائج التي توصل اليها الباحث يمكن استتاج ماياتي 1-التاكيد على على المعاني التي يدعوا لها القران الكريم وربطها بالحياة العملية r-ضرورة استخدام اللغة الفصحى في تدريس مادة القرآن الكريم والتربية الإسلامية

ثالثاً: :التوصيات

في ضوء نتائج البحث الحالي يوصي الباحث بماياتي

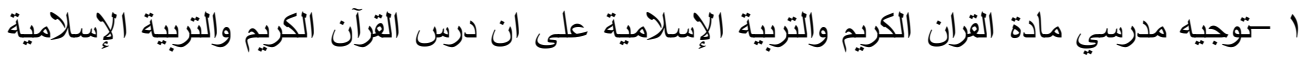
هو درس توجيه وتقويم r - الاهتمام بدرس مادة القران الكريم والتربية الإسلامية من قبل الادارات المدرسية ومدرسي المادة انفسهم رابعاً :المقترحات في ضوء النتائج يقترح الباحث ماياتي : ائي 1 - اجراء دراسات مماثلة على مراحل اخرى r - اجراء دراسة اوسع تكون العينة فيها على مستوى مديرية أو اكثر أخرى 


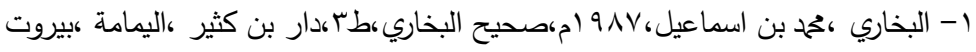

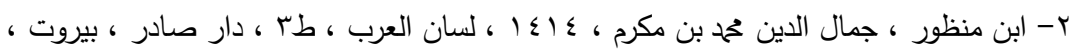

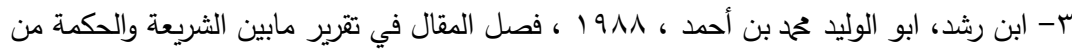

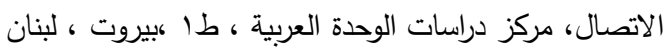

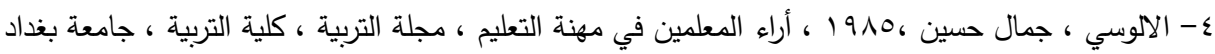

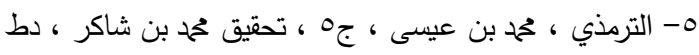

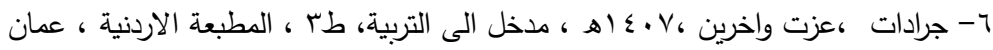
V

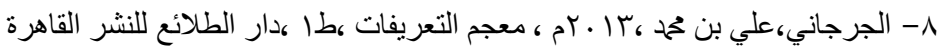

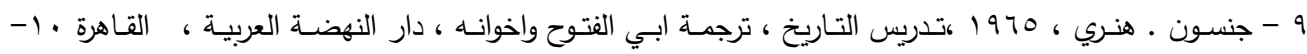

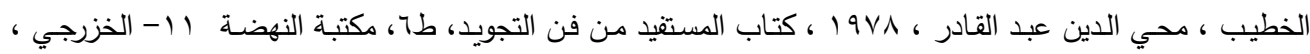

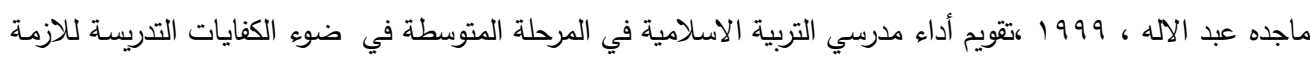

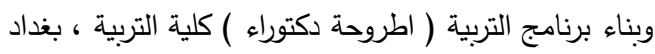

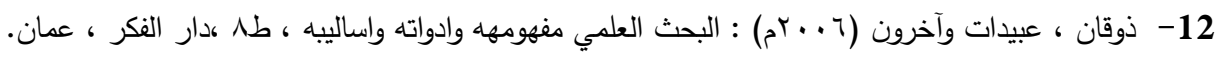

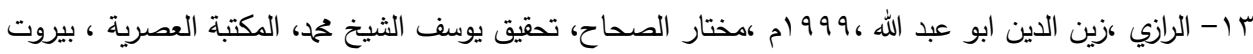

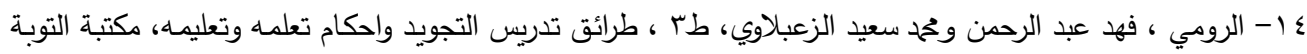
م الرياض

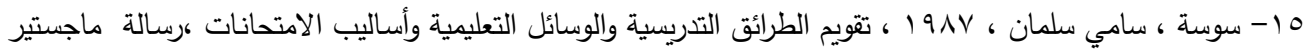

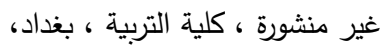

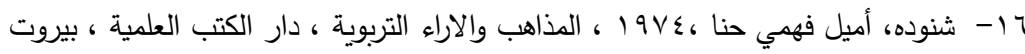
IV

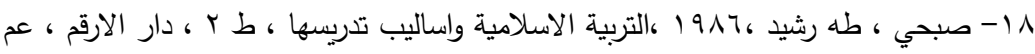

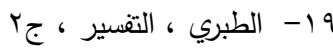

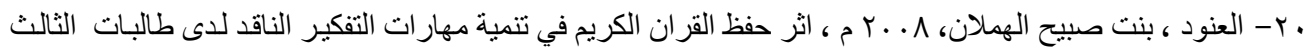

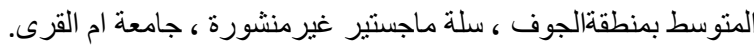

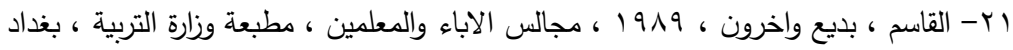

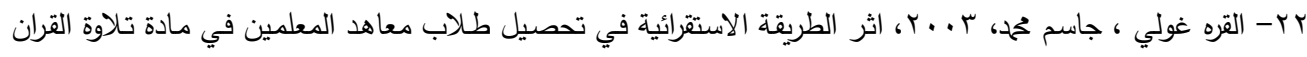

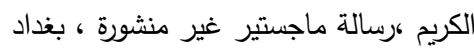

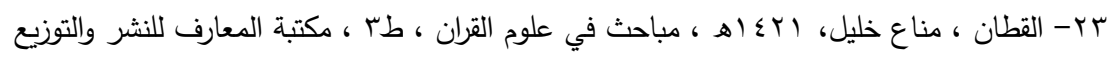
الرياض

؟ ؟- فوزي ، أحمد نصيف واخرون ،1990 ، الحله الايمانية ، وزارة التربية ، بغداد ، العراق 
العدد الثالث والأربعون

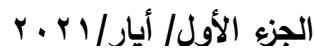

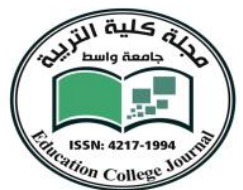

trion College

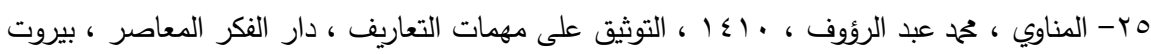

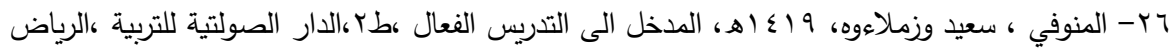

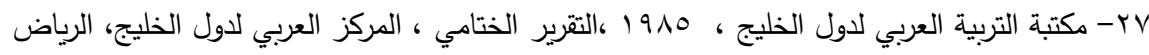

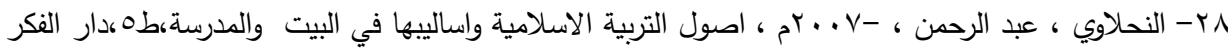

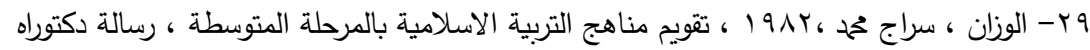

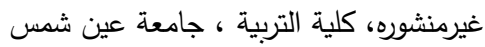

